\title{
Preterm Birth Contributes to Increased Vascular Resistance and Higher Blood Pressure in Adolescent Girls
}

\author{
ANNA-KARIN EDSTEDT BONAMY, ANA BENDITO, HELENA MARTIN, ELLIKA ANDOLF, \\ GUNNAR SEDIN, AND MIKAEL NORMAN \\ Department of Woman and Child Health [A.-K.E.B., A.B., H.M., M.N., G.S.], Karolinska Institutet, 17176 \\ Stockholm, Sweden; Karolinska Institutet at Danderyd Hospital [E.A.], 18288 Stockholm, Sweden; and \\ Uppsala University Children's Hospital, 75185 Uppsala, Sweden.
}

\begin{abstract}
Preterm birth might induce permanent changes in vascular structure and function as well as in blood pressure. To elucidate this hypothesis and underlying mechanisms in girls born before term, the authors correlated neonatal data, including estradiol levels, with vascular function and structure and with blood pressure after puberty. In a case-control study design, 34 girls born before term and 32 gender- and age-matched control infants born at term were included. Pulse wave analysis was used to determine aortic pressure profiles and overall arterial compliance. Stiffness of the carotid artery and abdominal aorta was measured with ultrasonography. Pulse wave velocity in the forearm was measured with photoplethysmography. A laser Doppler technique was used to determine skin perfusion before and after transdermal delivery of acetylcholine, an endothelium-dependent vasodilator. It was found that preterm girls had significantly higher brachial and aortic blood pressure, a narrower but less stiff abdominal aorta, and lower peripheral skin blood flow than did control infants. Augmentation index, carotid stiffness, pulse wave velocity, endothelium-dependent vasodilatation, and heart
\end{abstract}

\section{ABSTRACT}

rate were similar in the two groups. In the preterm group, blood pressure and vascular functions showed no association with intrauterine growth retardation or neonatal estradiol levels. In conclusion, preterm girls have higher blood pressure and an increased resistance in the vascular tree after puberty. These findings may have implications for future cardiovascular risk in the growing adult population surviving preterm birth. (Pediatr Res 58: 845-849, 2005)
Ach, acetylcholine

\section{Abbreviations}
AGA, appropriate for gestational age
AI, augmentation index
BMI, body mass index
BP, blood pressure
$\mathbf{C V}$, coefficient of variation
PU, perfusion unit
PWV, pulse wave velocity
SGA, small for gestational age

Adverse influences in early life have been held responsible for some of the morbidity and mortality from cardiovascular diseases in the adult population. Restricted growth in utero is thought to leave an imprint on various fetal organ systems that could increase the risk of coronary heart disease and hypertension later in life. Preterm birth is another occurrence in which differences in developmental conditions may significantly affect the vascular system, although the long-term consequences might differ from those of restricted fetal growth $(1,2)$. Adults

Received November 8, 2004; accepted April 6, 2005.

Correspondence: Anna-Karin Edstedt Bonamy, Astrid Lindgren Children's Hospital, Q9:00 Karolinska University Hospital Solna, 17176 Stockholm, Sweden; e-mail: anna-karin.edstedt.bonamy@ki.se.

Supported by the Swedish Research Council (projects 71P-14158, 73VX-14729), Swedish Heart Lung Foundation, Karolinska Institute Research Foundations, Sällskapet Barnavård, and HRH Crown Princess Lovisa's Memorial Fund.

DOI: 10.1203/01.PDR.0000181373.29290.80 born before term show an increase in BP and signs of an adverse metabolic profile $(1,3-8)$. The underlying mechanisms responsible for such long-term effects of preterm birth are not known.

Vascular, renal, and central regulatory factors have been proposed to be involved in the developmental programming of BP (9). Changes in sex hormones may also be involved. Fetal exposure to placental estrogens and progesterone normally increases markedly toward the end of pregnancy, and birth weight can be used as a proxy for antenatal estrogen exposure (10). After preterm birth, exposure to placental steroids abruptly ends. Preterm girls can, to various degrees, compensate for this loss by increasing endogenous estrogen production during the first months after birth (11). Whereas endogenous estrogens are known to have beneficial effects on arterial stiffness and endothelial function, offering cardioprotection in women of reproductive age, their role in early vascular devel- 
opment and their influence on later BP is far less clear $(12,13)$. Several facts justify further investigation. First, abnormal retinal vascularization has been proposed to be a general phenomenon after preterm birth, and experimental data show that estrogen can modulate this process $(1,14)$. Second, variations in neonatal gonadal hormones correlate with later BP in animal models of hypertension (15). Finally, a preterm drop in estrogen during angiogenesis might silence gene expression of estrogen receptors in the vascular tree, a phenomenon recently proposed to be linked to accelerated atherosclerosis (16).

We hypothesized that arterial stiffening and endothelial dysfunction increase BP in women born before term compared with those born at term. Within the preterm group, later vascular function and BP might be related to the degree of estrogen secretion in infancy. Between 1982 and 1989, in conjunction with the discovery of neonatal ovarian stimulation after preterm birth, estradiol levels were prospectively collected in all preterm girls born in Uppsala (11).

The aim of this controlled study was to determine BP, arterial stiffness, and endothelial function in this unique cohort of adolescent girls born before term.

\section{METHODS}

Subjects. Neonatal estradiol levels were collected prospectively in all preterm girls ( $\leq 34$ weeks of gestation) born between 1982 and 1989 in Uppsala. All survivors without major disabilities $(n=60)$ were invited to participate by letter, and 34 of them agreed to take part. The nonresponders did not differ significantly from the participants regarding gestational age, birth weight, fetal growth restriction, or preeclampsia. In the preterm study group, 25 girls were defined as having been AGA (birth weight = mean $\pm 2 \mathrm{SD}$ ), and 9 were SGA (birth weight below mean -2 SD), according to Swedish reference data for intrauterine fetal growth (17). The cause of preterm birth was bleeding in 8 cases (24\%), premature rupture of membranes or preterm labor in $11(32 \%)$, preeclampsia in $12(35 \%)$, Rh immunization in $2(6 \%)$, and intrauterine growth retardation in $1(3 \%)$. There was no case of intrauterine infection. Age-matched control girls $(n=32)$ were chosen from healthy volunteers who were born at term and were AGA. Perinatal data were obtained from medical records. The family history of cardiovascular diseases (coronary heart disease, stroke, hypertension, hyperlipidemia) among first- and seconddegree relatives was obtained. Weight, height, and waist circumference were measured, and BMI was calculated. Data on the participants are summarized in Table 1.

Informed consent was obtained from the girls and their parents before the investigation. The Ethics Committee approved the study protocol.

Neonatal estradiol determinations. In infancy the preterm girls had their levels of estradiol analyzed by radio-immuno-assay. Blood was collected at the postconceptional ages of $32(0.3), 38(0.3)$, and $46(0.4)$ weeks (mean [SEM] values), i.e. three times for each girl. To evaluate the role of neonatal estradiol levels for later BP and vascular function, both individual mean and maximum values were used.

Blood pressure. The measurements were performed between 8 am and 1 $\mathrm{pm}$. All participants were fasting but were allowed to drink water, and they had refrained from smoking, coffee, aspirin, and antioxidants on the day of the examinations. The heart rate and brachial $\mathrm{BP}$ were recorded with an automated oscillometric method, by use of an appropriately sized arm cuff, after $10 \mathrm{~min}$ rest in the supine position (Boso Medicus, Bosch+Sohn GmbH u. Co., Jungingen, Germany). A mean value of nine consecutive determinations taken at intervals of at least $3 \mathrm{~min}$ was regarded as the participant's BP. The intrasubject CV for repeated measurements was $5.4 \%$ for systolic BP and $6.1 \%$ for diastolic BP.

Pulse wave analysis. A pulse wave analysis system (SCOR-Px, AtCor Medical, West Ryde, Australia) was used together with applanation tonometry (Millar transducer SPT-301, Millar Instruments, Houston, Texas, USA) to noninvasively acquire the radial artery pressure waveforms. These waveforms were calibrated to conventionally measured brachial BP. Central aortic waveforms were derived from those obtained from the radial artery using a data transfer algorithm, validated in adults $(18,19)$. From the aortic waveforms, the central systolic and diastolic BPs were determined.
Table 1. Characteristics of girls in the study

\begin{tabular}{|c|c|c|c|}
\hline & $\begin{array}{c}\text { Study } \\
\text { group } \\
n=34\end{array}$ & $\begin{array}{c}\text { Control } \\
\text { group } \\
n=32\end{array}$ & $p$ value \\
\hline $\begin{array}{l}\text { Family history of cardiovascular } \\
\text { disease }(n)\end{array}$ & 26 & 20 & 0.15 \\
\hline \multicolumn{4}{|l|}{ Perinatal data } \\
\hline Maternal age (y) & $30 \quad(0.9)$ & $28 \quad(0.7)$ & 0.20 \\
\hline Primipara $(n)$ & 16 & 16 & 0.60 \\
\hline Smoking in pregnancy (n) & 10 & 5 & 0.10 \\
\hline Preeclampsia $(n)$ & 12 & 0 & $<0.0001$ \\
\hline Antenatal steroid treatment $(n)$ & 2 & - & \\
\hline Cesarean section $(n)$ & 25 & 6 & $<0.0001$ \\
\hline Length of gestation (w) & $29.1(0.5)$ & $39.6(0.2)$ & $<0.0001$ \\
\hline Range & $23-34$ & $38-41$ & \\
\hline Birth weight $(\mathrm{g})$ & $1343 \quad(81)$ & $3602 \quad(58)$ & $<0.0001$ \\
\hline Range & $649-2684$ & $3020-4220$ & \\
\hline SGA $(n)$ & 9 & 0 & $<0.0001$ \\
\hline \multicolumn{4}{|l|}{ Current data } \\
\hline Age (y) & $16.5(0.3)$ & $16.5(0.3)$ & 0.91 \\
\hline Age at menarche $(y)$ & $12.7(0.2)$ & $13.1(0.2)$ & 0.11 \\
\hline LMP (days after) & $14 \quad(1.4)$ & 13 (1.6) & 0.57 \\
\hline Oral contraception (n) & 8 & 7 & 0.77 \\
\hline Smokers (n) & 2 & 2 & 0.97 \\
\hline Weight $(\mathrm{kg})$ & $(2.2)$ & (1.3) & 0.76 \\
\hline Height $(\mathrm{cm})$ & $(1.0)$ & (1.1) & 0.03 \\
\hline $\operatorname{BMI}\left(\mathrm{kg} / \mathrm{m}^{2}\right)$ & $(0.7)$ & $(0.5)$ & 0.23 \\
\hline Waist circumference $(\mathrm{cm})$ & $72 \quad(1.7)$ & $68 \quad(0.9)$ & 0.06 \\
\hline
\end{tabular}

Data are mean (SEM) or number of subjects. SGA, small for gestational age (birth weight $<$ mean -2 SD for gestational age); LMP, last menstrual period; BMI, body mass index.

The sum of the mechanical properties in elastic and muscular arteries determines the velocity of the outgoing systolic pressure wave and the extent to which this wave is reflected back to the proximal aorta. The reflected waves augment the forward traveling pressure wave generated by left ventricular ejection. Identification of early and late systolic peaks in the aortic pressure curve allows quantification of an AI, presented at a standardized heart rate of 75 beats/min. The AI is related to the speed of the central and peripheral pressure wave reflections and can therefore be used to estimate total arterial stiffness. The mean value of three recordings, each comprising 10 consecutive pressure waves, was taken as the individual's reading. The $\mathrm{CV}$ for $\mathrm{AI}$ measurements was $9.7 \%$.

Stiffness in the aorta and carotid artery. The mechanical properties of two elastic arteries were studied by measuring changes in diameter of the abdominal aorta and the left common carotid artery (20). A real-time B mode ultrasonic scanner (Hitachi EUB 240, Hitachi Medical Corp., Tokyo, Japan) with a 5-MHz linear array transducer (Hitachi EZU-PL22, Tokyo, Japan) was interfaced with a computer-generated pair of electronic echo trackers (Diamove, Teltec AB, Lund, Sweden) to measure the pulsatile movements of the vessel wall. Ultrasonic signals were sampled at a frequency of $100 \mathrm{MHz}$, implying that the system could detect vessel wall movements of less than 10 $\mu \mathrm{m}$. The end diastolic diameter (Dd, $\mathrm{mm}$ ) and the pulse amplitude of the diameter $(\Delta \mathrm{D}, \mathrm{mm})$ were determined. These data and those of simultaneously measured BPs in the brachial artery were computed to yield the stiffness index $(\beta)$ of the arterial wall at the selected sites by the following equation:

$$
\beta=\frac{\ln (\mathrm{SBP} / \mathrm{DBP})}{\Delta \mathrm{D}} \times \mathrm{Dd}
$$

The mean value of three recordings, each comprising six to 10 consecutive heart cycles, was regarded as the individual's reading. The CV for repeated measurements of arterial stiffness index has been found to be $10-13 \%$ at our laboratory.

Pulse wave velocity. The PWV was measured to estimate arterial stiffness in a muscular artery. It is related to arterial vessel wall compliance: i.e. in a stiffer artery, the pulse wave travels faster. A photoplethysmographic method was used to determine the transit time of the arterial pulse wave from the brachial artery (antecubital fossa) to the radial artery just proximal to the wrist (mean interprobe distance of $233 \mathrm{~mm}(\mathrm{SEM}=1.8)$ as determined with a measuring tape graded in millimeters) (21). The mean transit time for at least 
10 heart cycles was calculated and divided by the distance between the probes. The PWV measurements were repeated three times in each participant, and the CV was $19 \%$.

Endothelial function. A laser Doppler instrument (Periflux 4001, laser wavelength $780 \mathrm{~nm}$ ) and a micropharmacology system were used to measure blood flow in the dorsal hand skin (Perimed AB, Kista, Sweden) $(2,20)$. The laser Doppler signal is proportional to the number and velocity of moving blood cells in the skin microvessels and is expressed in PU of output voltage $(1 \mathrm{PU}=10 \mathrm{mV})$. The temperature of the laser Doppler probe was standardized to $32^{\circ} \mathrm{C}$. To study endothelium-dependent vasodilatation, basal perfusion was recorded for $\geq 2 \mathrm{~min}$, after which $2 \%$ Ach (acetylcholine chloride, Sigma Chemical Co.-Aldrich Chemie GmbH, Steinheim, Germany) was transferred across the skin by iontophoresis (anodal current of $0.1 \mathrm{~mA}$ for $20 \mathrm{~s}$ repeated five times at 60-s intervals). Basal perfusion and changes in response to $\mathrm{ACh}$ were measured as the area under the PU/time curve. This endothelial function test in the skin correlates to flow mediated dilatation in the brachial artery (22). The CV for repeated measurements of maximum perfusion change induced by $\mathrm{ACh}$ has been found to be $18 \%$ in our laboratory.

Statistical methods. The results are presented as mean (SEM) or proportions. Student's $t$ test, $\chi^{2}$, and analysis of variance were used to test for group differences. Correlation coefficients were calculated to find possible associations. Regression analysis was used to evaluate contributions to group differences in BP and vascular functions (outcomes). In these calculations, a family history of cardiovascular disease was considered as a potential confounder Advanced maternal age, smoking in pregnancy, preeclampsia, gestational age and SGA at birth were considered to be perinatal exposures possibly related to outcomes. In addition, factors known to affect BP and vascular outcomes, such as current weight, height, smoking, age at menarche and oral contraception were investigated. Initially, simple regression was performed. Independent variables with $p<0.20$ in these calculations were entered into a multiple regression model. Analysis of variance for repeated measurements was used to assess perfusion responses to ACh. A $p$ value of 0.05 was considered significant.

\section{RESULTS}

There were no group differences in age (mean $16.5 \mathrm{y}$ ), smoking, use of oral contraceptives, age at menarche, or menstrual cycle phase. The preterm girls were shorter than the control girls and had a larger waist circumference, although no difference in BMI was noted (Table 1).

Neonatal estradiol levels varied from 9 to $775 \mathrm{pmol} / \mathrm{L}$ (Table 2). According to variance analysis, $40 \%$ of the estimated total variance could be attributed to interindividual differences in estradiol levels.

Brachial blood pressure. Preterm girls had significantly higher BP than control girls born at term (Table 3), and four preterm girls had BP in the hypertensive range: age- and height-adjusted $\mathrm{BP} \geq 90$ th percentile on the study day.

By use of multiple regression analysis, brachial SBP was independently related to preterm birth, a family history of cardiovascular disease, height, and smoking, but not to age, waist circumference, BMI, age at menarche, use of oral contraceptives, or heart rate. A corresponding analysis with diastolic BP as the dependent variable showed significant relations to preterm delivery, smoking, and heart rate (Table 4). The pulse pressure was associated with preterm birth and height. In

Table 2. Estradiol concentrations at different postconceptional ages in preterm girls

\begin{tabular}{lcc}
\hline Estradiol samples & $\begin{array}{c}\text { Mean postconceptional } \\
\text { age weeks (SEM) }\end{array}$ & $\begin{array}{c}\text { Estradiol concentration, } \\
\text { pmol/L } \\
\text { median (range) }\end{array}$ \\
\hline $1(n=34)$ & $32(0.3)$ & $70(21-660)$ \\
$2(n=33)$ & $38(0.3)$ & $94(10-775)$ \\
$3(n=28)$ & $46(0.4)$ & $72(9-189)$ \\
\hline
\end{tabular}

Table 3. Blood pressure $(\mathrm{mm} \mathrm{Hg})$ and heart rate (beats/min)

\begin{tabular}{lccc}
\hline & $\begin{array}{c}\text { Study group } \\
(n=34)\end{array}$ & $\begin{array}{c}\text { Control group } \\
(n=32)\end{array}$ & $p$ \\
\hline Brachial SBP & $115(1.5)$ & $104(1.6)$ & $<0.001$ \\
Brachial DBP & $68(1.0)$ & $63(1.0)$ & $<0.001$ \\
Brachial PP & $46(1.0)$ & $41(1.0)$ & $<0.001$ \\
Aortic SBP & $100(1.4)$ & $93(1.5)$ & 0.001 \\
Aortic DBP & $70(1.2)$ & $66(1.3)$ & 0.03 \\
Heart rate & $67(2.0)$ & $65(2.0)$ & 0.58 \\
\hline
\end{tabular}

Data are mean (SEM)

SBP, systolic blood pressure; DBP, diastolic blood pressure; PP, pulse pressure.

Table 4. Factors independently related to blood pressure in two groups of adolescent girls born before term $(n=34)$ or at term $(n=32)$

\begin{tabular}{llcc}
\hline Dependent variable & \multicolumn{1}{c}{ Regression factor } & Regression coefficient & $p$ \\
\hline SBP & Preterm birth & 5.7 & $<0.001$ \\
& Smoking & 4.2 & 0.02 \\
& Family history of CVD & 2.0 & 0.05 \\
DBP & Height (cm) & 0.5 & 0.008 \\
& Preterm birth & 2.7 & $<0.001$ \\
& Smoking & 3.2 & 0.01 \\
& Heart rate & 0.18 & 0.007 \\
\hline
\end{tabular}

SBP, systolic blood pressure; DBP, diastolic blood pressure; CVD, cardiovascular disease.

addition, the pulse pressure correlated with systolic BP $(r=$ $0.82, p<0.0001)$ and diastolic $\mathrm{BP}(r=0.33, p=0.006)$.

Aortic blood pressure and augmentation index. According to pulse wave analysis, the aortic BP was significantly higher in preterm girls than in control girls (Table 3). The AI was $-2.4 \%$ (1.7) in preterm girls and $-4.2 \%$ (1.8) in the control group $(p=0.46)$. The AI did not correlate with any of the independent background variables.

Elastic arteries: dimensions and stiffness. Preterm girls had narrower abdominal aortas than did the control girls: the end diastolic diameter was $10.0 \mathrm{~mm}(0.2)$ compared with $11.0 \mathrm{~mm}$ (0.3) in the control group $(p=0.01)$. The relative pulsatile diameter change-i.e. the vessel wall strain-was $15.9 \%(0.7)$ in the aorta of preterm girls and $13.4 \%(0.8)$ in the control group $(p=0.03)$. The preterm girls had $15 \%$ lower aortic stiffness than did the control girls $(p=0.02)$ (Table 5).

Multivariate analysis, including height and weight in the regression model, showed that in addition to group, the aortic diameter also correlated positively with age $(r=0.42, p=$ $0.01)$.

In both groups, the average carotid diameter was $6.5 \mathrm{~mm}$ $(0.1)$, and the carotid strain and stiffness were similar. In the multivariate analysis, lower carotid strain was associated with later menarche $(p<0.01)$.

Table 5. Aortic indices in healthy adolescent girls born before term $(n=34)$ or at term $(n=32)$

\begin{tabular}{lccc}
\hline & \multicolumn{3}{c}{ Control } \\
& Study group & group & $p$ \\
\hline End diastolic diameter $(\mathrm{mm})$ & $10.0(0.25)$ & $11.0(0.26)$ & 0.01 \\
Strain & $0.16(0.007)$ & $0.13(0.008)$ & 0.03 \\
Stiffness index & $3.3(0.17)$ & $3.9(0.18)$ & 0.02 \\
\hline
\end{tabular}

Data are mean (SEM). 
Brachial BP showed no correlation with aortic and carotid end diastolic diameters. Aortic and carotid strain correlated with pulse pressure ( $r=0.26$ and 0.39 , respectively, $p<0.05$ ).

Muscular arteries: pulse wave velocity. The brachioradial PWV was $7.8 \mathrm{~m} / \mathrm{s}(0.4)$ in girls born before term and $7.5 \mathrm{~m} / \mathrm{s}$ $(0.4)$ in control girls $(p=0.54)$. In the regression model, the PWV was related to smoking ( $\beta=1.6, p=0.007)$, age at menarche ( $\beta=0.63, p=0.04)$, and BMI $(\beta=0.19, p=0.02)$.

The PWV correlated to BP $(r=0.42$ for systolic BP, $r=$ 0.57 for diastolic BP, $p<0.001)$. After adjustment for BP, the group difference in PWV remained insignificant.

Skin blood flow and endothelial function. Resting skin perfusion was lower in preterm girls than in control girls (mean 5.9 versus $9.5 \mathrm{PU}, p=0.01$ ). The maximum increase in perfusion induced by the endothelium-dependent vasodilator $\mathrm{ACh}$, however, was similar in the groups (107 PU (8.8) in preterm girls and $117 \mathrm{PU}$ (9.0) in control girls (Fig. 1).

Resting skin perfusion correlated with preterm birth and age $(p<0.05)$. The $\mathrm{ACh}$ response was higher in girls using oral contraceptives (mean $137 \mathrm{PU}, n=15$ ) than in those who did not $(107 \mathrm{PU}, p=0.01)$. We found no other associations between endothelium-dependent vasodilatation and background variables, including smoking. BP correlated inversely with basal skin perfusion ( $r=-0.33$ for systolic BP, $r=$ -0.30 for diastolic BP, $p \leq 0.01)$.

Blood pressure and vascular functions in relation to neonatal estradiol, preeclampsia, and fetal growth restriction. In the preterm group, no significant associations were seen between neonatal estradiol levels, maternal preeclampsia, gestational age, or SGA at birth and later BP, arterial stiffness, or endothelial function.

Relation between vascular measures. Besides the relations to BP, the different measures of arterial stiffness and endothelial function were not interrelated.

\section{DISCUSSION}

The most important findings in the present study are that preterm adolescent girls had significantly higher BP, narrower aorta, and lower peripheral blood flow-i.e. increased vascular resistance- than did age-matched control girls born at term. By contrast, we found no evidence of endothelial dysfunction or arterial stiffening related to preterm birth

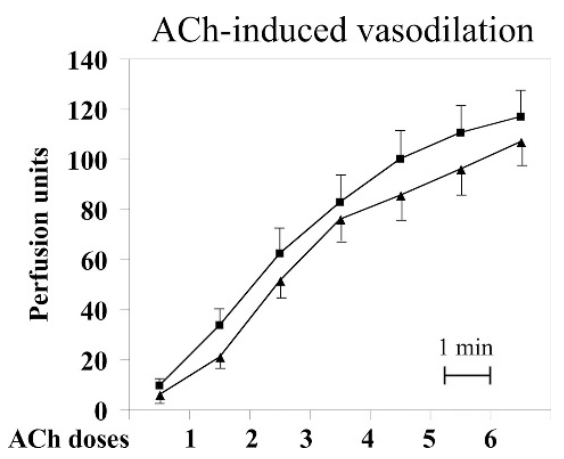

Figure 1. Skin perfusion in response to ACh (an endothelium-dependent vasodilator) in healthy adolescent girls born before term $(n=34)$ and control girls born at term $(n=32)$. Mean (SEM) values. Control; $\leftarrow$ Preterm.
The authors of a systematic review of the literature concluded that there was no consistent relation between preterm delivery and systolic BP (23). However, the findings of recent large epidemiologic studies suggest that preterm birth contributes to higher systolic BP in young men $(6,7)$. This effect of preterm birth on BP in adult life has been reported to increase as gestation shortens $(3,6,7)$. This could be one explanation for the lack of an association in early studies of BP in old adults, in whom survival after preterm birth was possible only after a slight shortening of gestation. Follow-up studies, including ambulatory 24-h BP measurements in very preterm girls and women, accord with our findings $(4,5,8)$.

Formula feeding of preterm infants has been associated with a higher BP in adolescence (24). During the neonatal period, the preterm girls in the present study received breast milk, either from the mother or banked, and a vast majority of the full-term control infants were exclusively breastfed at 2 months of age. Consequently, the results in the present study should not have been affected by differences in neonatal nutrition.

The finding of a narrower abdominal aorta in preterm girls despite a higher distending pressure indicates that the difference in diameter has a structural basis. The reduced caliber of the aorta in preterm girls may be partly related to their lower height. Another unexplored hypothesis concerns the possibility of halted aortic development after preterm birth. In utero, more than $50 \%$ of the cardiac output is accommodated by the abdominal aorta on its way to the placenta. With the birthrelated cessation of placental circulation, blood flow in the abdominal aorta is significantly reduced. The reduction in aortic flow leads to a transient growth arrest in this part of the vascular tree (25). We suggest that if this occurs well before term, it could result in a permanent narrowing of the abdominal aorta. Moreover, most of the preterm girls in this study (26/34) had had an umbilical artery catheter in the abdominal aorta. Umbilical artery catheters further reduce aortic blood flow and have previously been associated with vascular damage and thromboembolism. Because we measured the luminal diameter of the aorta, our findings do not exclude the presence of an increased aortic wall thickness. Thickening of the intima media, an early pathophysiologic event in atheroma formation, has been found in children (26).

Surprisingly, preterm girls showed reduced aortic stiffness index, a finding that could not be attributed to differences in pressures or vessel dimensions. Experimental data suggest that an initial increase in aortic elasticity may precede later stages of accelerated arterial stiffening and atheroma formation (27). Because the abdominal aorta is a predilection site for later atherosclerosis, longitudinal studies are needed to enable a full understanding of the significance of altered aortic stiffness in individuals born before term.

Endothelial dysfunction - a key factor in the early stages of atheroma formation-has been found in the neonatal skin microcirculation as well as in the brachial artery in children and adults born small and lean at term $(20,28,29)$. The present study confirms previous observations in infants and adolescents that preterm birth, alone or in combination with being SGA, does not contribute to endothelial dysfunction $(2,30)$. A reduction in skin capillary density has been reported in indi- 
viduals with essential hypertension and has been suggested to be a primary structural abnormality of the vascular tree in children of low birth weight, before the rise in BP occurs $(31,32)$. However, in a recent study, there was no evidence of reduced capillary density in children and adults born before term (33). Nevertheless, our finding of an inverse correlation between resting skin perfusion and BP indicates that the preterm individuals have an increased peripheral vascular resistance, possibly on a functional basis.

Our findings of relations between BP and forearm PWV are in line with previous brachial artery findings in children $(34,35)$. However, in healthy adolescent girls, we found no relations between systemic AI, local stiffness indices of elastic arteries, and forearm PWV. The fairly high coefficient of variation for PWV measurements could have contributed to the absence of correlations. Another explanation is that the elastic properties are not uniformly distributed within the vascular tree, with fundamental differences between muscular and elastic arteries. Because large arteries exhibit differential changes in stiffness with aging, later interrelations between the different vascular measures cannot be excluded (36). Finally, the transfer algorithm for determination of AI, shown to be accurate in older adults, has not been invasively validated in adolescents (18).

Our findings suggest that variations in neonatal estradiol levels in preterm girls contribute little if any to later differences in vascular functions and BP. Nevertheless, we regard those findings as preliminary because the long-term developmental role of premature loss of the placenta as an endocrine organ remains obscure. When the marked increase in estrogen during the last trimester of pregnancy is considered, the control girls born at term had been exposed to much higher estrogen levels during late fetal life (10). Although not equivalent to conditions after preterm birth, placental insufficiency in term pregnancies is associated with lower estrogen levels at birth, growth retardation of the baby, and endothelial dysfunction (28,37). Given our hypothesis, boys should be more affected by preterm birth. In accordance, very low birth weight boys have been shown to have higher BP than girls in late adolescence (8).

Small group differences in vascular outcomes that may become larger and more important later on in life could have passed undetected because of limitations in power.

In summary, the finding of significant increases in BP and vascular resistance in preterm individuals at young ages may have implications for the prevalence of cardiovascular and renal diseases. The number of infants surviving very preterm birth is steadily increasing. Future research should aim at further clarification of the causes of an increase in BP and continued long-term follow-up of these individuals.

\section{REFERENCES}

1. Kistner A, Jacobson L, Jacobson SH, Svensson E, Hellstrom A 2002 Low gestational age associated with abnormal retinal vascularization and increased blood pressure in adult women. Pediatr Res 51:675-680

2. Norman M, Martin H 2003 Preterm birth attenuates association between low birth weight and endothelial dysfunction. Circulation 108:996-1001

3. Siewert-Delle A, Ljungman S 1998 The impact of birth weight and gestational age on blood pressure in adult life: a population-based study of 49-year-old men. Am J Hypertens 11:946-953

4. Kistner A, Celsi G, Vanpee M, Jacobson SH 2000 Increased blood pressure but normal renal function in adult women born preterm. Pediatr Nephrol 15:215-220

5. Irving RJ, Belton NR, Elton RA, Walker BR 2000 Adult cardiovascular risk factors in premature babies. Lancet 355:2135-2136
6. Leon DA, Johansson M, Rasmussen F 2000 Gestational age and growth rate of fetal mass are inversely associated with systolic blood pressure in young adults: an epidemiologic study of 165,136 Swedish men aged 18 years. Am J Epidemiol 152:597-604

7. Lundgren EM, Cnattingius HM, Jonsson GB, Tuvemo TH 2001 Linear catch-up growth does not increase the risk of elevated blood pressure and reduces the risk of overweight in males. J Hypertens 19:1533-1538

8. Doyle LW, Faber B, Callanan C, Morley R 2003 Blood pressure in late adolescence and very low birth weight. Pediatrics 111:252-257

9. Gluckman PD, Hanson MA 2004 Developmental origins of disease paradigm: a mechanistic and evolutionary perspective. Pediatr Res 56:311-317

10. Kaijser M, Jacobsen G, Granath F, Cnattingius S, Ekbom A 2002 Maternal age, anthropometrics and pregnancy oestriol. Paediatr Perinat Epidemiol 16:149-153

11. Sedin G, Bergquist C, Lindgren PG 1985 Ovarian hyperstimulation syndrome in preterm infants. Pediatr Res 19:548-552

12. Virdis A, Ghiadoni L, Pinto S, Lombardo M, Petraglia F, Gennazzani A, Buralli S, Taddei S, Salvetti A 2000 Mechanisms responsible for endothelial dysfunction associated with acute estrogen deprivation in normotensive women. Circulation $101: 2258-2263$

13. Mendelsohn ME, Karas RH 1994 Estrogen and the blood vessel wall. Curr Opin Cardiol 9:619-626

14. Miyamoto N, Mandai M, Takagi H, Suzuma I, Suzuma K, Koyama S, Otani A, Oh H, Honda Y 2002 Contrasting effect of estrogen on VEGF induction under different oxygen status and its role in murine ROP. Invest Ophthalmol Vis Sci 43:2007-2014

15. Rowland NE, Fregly MJ 1992 Role of gonadal hormones in hypertension in the Dahl salt-sensitive rat. Clin Exp Hypertens A 14:367-375

16. Dong C, Yoon W, Goldschmidt-Clermont PJ 2002 DNA methylation and atherosclerosis. J Nutr 132:2406S-2409S

17. Marsal K, Persson PH, Larsen T, Lilja H, Selbing A, Sultan B 1996 Intrauterine growth curves based on ultrasonically estimated foetal weights. Acta Paediatr 85:843-848

18. Pauca AL, O'Rourke MF, Kon ND 2001 Prospective evaluation of a method for estimating ascending aortic pressure from the radial artery pressure waveform. Hypertension 38:932-937

19. Oliver JJ, Webb DJ 2003 Noninvasive assessment of arterial stiffness and risk of atherosclerotic events. Arterioscler Thromb Vasc Biol 23:554-566

20. Martin H, Hu J, Gennser G, Norman M 2000 Impaired endothelial function and increased carotid stiffness in 9-year-old children with low birthweight. Circulation 102:2739-2744

21. Loukogeorgakis S, Dawson R, Philips N, Martyn CN, Greenwald SE 2002 Validation of a device to measure arterial pulse wave velocity by a photo-plethysmographic method. Physiol Meas 23:581-596

22. Hansell J, Henareh L, Agewall S, Norman M 2004 Non-invasive assessment of endothelial function: relation between vasodilatory responses in skin microcirculation and brachial artery. Clin Physiol Funct Imaging 24:317-322

23. Huxley RR, Shiell AW, Law CM 2000 The role of size at birth and postnatal catch-up growth in determining systolic blood pressure: a systematic review of the literature. J Hypertens 18:815-831

24. Singhal A, Cole TJ, Lucas A 2001 Early nutrition in preterm infants and later blood pressure: two cohorts after randomised trials. Lancet 357:413-419

25. Langille BL, Brownlee RD, Adamson SL 1990 Perinatal aortic growth in lambs: relation to blood flow changes at birth. Am J Physiol 259:H1247-H1253

26. Berenson GS, Srinivasan SR, Bao W, Newman WP 3rd, Tracy RE, Wattigney WA 1998 Association between multiple cardiovascular risk factors and atherosclerosis in children and young adults. The Bogalusa Heart Study. N Engl J Med 338:1650-1656

27. Farrar DJ, Bond MG, Riley WA, Sawyer JK 1991 Anatomic correlates of aortic pulse wave velocity and carotid artery elasticity during atherosclerosis progression and regression in monkeys. Circulation 83:1754-1763

28. Martin H, Gazelius B, Norman M 2000 Impaired acetylcholine-induced vascular relaxation in low birth weight infants: implications for adult hypertension? Pediatr Res 47:457-462

29. Leeson CP, Whincup PH, Cook DG, Mullen MJ, Donald AE, Seymour CA, Deanfield JE 2000 Cholesterol and arterial distensibility in the first decade of life: a populationbased study. Circulation 101:1533-1538

30. Singhal A, Kattenhorn M, Cole TJ, Deanfield J, Lucas A 2001 Preterm birth, vascular function, and risk for atherosclerosis. Lancet 358:1159-1160

31. Antonios TF, Singer DR, Markandu ND, Mortimer PS, MacGregor GA 1999 Rarefaction of skin capillaries in borderline essential hypertension suggests an early structural abnormality. Hypertension 34:655-658

32. Ijzerman R, van Weissenbruch MM, Voordouw JJ, Yudkin JS, Serne EH, Delemarrevan de Waal HA, Stehouwer CD 2002 The association between birth weight and capillary recruitment is independent of blood pressure and insulin sensitivity: a study in prepubertal children. J Hypertens 20:1957-1963

33. Irving RJ, Shore AC, Belton NR, Elton RA, Webb DJ, Walker BR 2004 Low birth weight predicts higher blood pressure but not dermal capillary density in two populations. Hypertension 43:610-613

34. Leeson CP, Whincup PH, Cook DG, Donald AE, Papacosta O, Lucas A, Deanfield JE 1997 Flow-mediated dilation in 9- to 11-year-old children: the influence of intrauterine and childhood factors. Circulation 96:2233-2238

35. Cheung YF, Wong KY, Lam BC, Tsoi NS 2004 Relation of arterial stiffness with gestational age and birth weight. Arch Dis Child 89:217-221

36. Lanne T, Hansen F, Mangell P, Sonesson B 1994 Differences in mechanical properties of the common carotid artery and abdominal aorta in healthy males. J Vasc Surg 20:218-225

37. Reynolds JW, Barnhart BJ, Carlson CV 1986 Feto-placental steroid metabolism in growth retarded human fetuses. Pediatr Res 20:166-168 